\title{
Dose-Dependent Inhibition of Angiotensin Converting Enzyme by Enalapril in Cats
}

\author{
Masami UECHI ${ }^{1)}$, Shigeki IMAMOTO ${ }^{1)}$ and Yumi ISHIKAWA ${ }^{1)}$ \\ 1) Veterinary Teaching Hospital, Kitasato University, 23-35-1 Higashi, Towada, Aomori 034-8628, Japan
}

(Received 5 October 2001/Accepted 27 December 2001)

ABSTRACT. Although heart failure in cats is treated with angiotensin converting enzyme (ACE) inhibitors, data on the effects of different doses of enalapril on hemodynamics and the inhibition of ACE activity have not been published. To evaluate the effect of enalapril, $0.25,0.5$, or $1.0 \mathrm{mg} / \mathrm{kg}$ was given once (s.i.d., p.o.) or twice (b.i.d., p.o.) a day, and plasma ACE activity, indirect blood pressure, and heart rate were measured. Plasma ACE activity and blood pressure fell dose-dependently. There was a biphasic effect on blood pressure with twice daily administration. Enalapril $0.25 \mathrm{mg} / \mathrm{kg}$ b.i.d. inhibited plasma ACE activity by $40 \%$ after $24 \mathrm{hr}$, which was almost the same as the effect of 0.5 and $1.0 \mathrm{mg} / \mathrm{kg}$ s.i.d., and 0.5 and $1.0 \mathrm{mg} / \mathrm{kg}$ b.i.d., while $0.25 \mathrm{mg} / \mathrm{kg}$ s.i.d. inhibited it by $23 \%$. Thus, enalapril with a daily dose exceeding $0.5 \mathrm{mg} / \mathrm{kg}$ may provide similar efficacy of ACE inhibition in cats.

KEY WORDS: angiotensin converting enzyme, enalapril, feline.

J. Vet. Med. Sci. 64(4): 385-387, 2002

Angiotensin converting enzyme (ACE) inhibitors have been used to treat mild to severe heart failure in humans and dogs $[1,4,6-8,14,19]$. In cats, there are several clinical reports of treating dilated and hypertrophic cardiomyopathy with ACE inhibitors $[5,12,13,16]$. Although the current recommended treatment for cardiac hypertrophy in cats is to use diltiazem first and then switch to a $\beta$ blocker if the clinical response is not optimal [11], a plasma ACE inhibitor may also be useful for treating certain feline diseases, notably congestive heart failure, hypertension, and chronic renal disease. However, the depressor or ACE inhibitory effects of ACE inhibitors such as enalapril in cats have not been published. The objective of this study was to determine the dose response of enalapril on hemodynamics and plasma ACE activity. To evaluate the effect of enalapril, cats were given $0.25,0.5$, or $1.0 \mathrm{mg} / \mathrm{kg}$ once or twice daily, and the plasma ACE activity, indirect blood pressure, and heart rate were measured.

This study followed the Guidelines for Institutional Laboratory Animal Care and Use of the School of Veterinary Medicine and Animal Science at Kitasato University.

This study used 8 clinically healthy cats (4 males, 4 females), weighing $3.5-5.3 \mathrm{~kg}$, for which routine laboratory tests, including hematological examinations and urinalysis, were normal. The cats were housed in cages and fed with commercial cat food twice a day (Hill's Colgate, Tokyo, Japan) at 10:00 and 22:00. Water was given ad libitum. Placebo or enalapril $\left(0.25,0.5\right.$, or $1.0 \mathrm{mg} / \mathrm{kg}$, Enacard ${ }^{\circledR}$, Merial Japan, Tokyo, Japan) was orally administered once a day at 10:00 or twice a day at 10:00 and 22:00. The interval of each dose was taken at least 3 days. Blood for measuring plasma ACE activity was drawn from the jugular vein before administration at baseline and after administration at $3,6,12$, and $24 \mathrm{hr}$ in the once a day protocol, or at baseline and after administration at 3, 6, 12, 15, 18, and $24 \mathrm{hr}$ in the twice a day protocol. Blood was immediately heparinized and centrifuged at $1,000 \mathrm{~g}$, and the supernatant was kept at $-80^{\circ} \mathrm{C}$. The heart rate and blood pressure at baseline and after enalapril administration $(3,6,12,15,18$, and $24 \mathrm{hr})$ were measured by oscillometric methods with an appropriately sized cuff placed over one forelimb. Five consecutive measurements were averaged.

Plasma ACE activity was measured using a commercial kit (ACE Color ${ }^{\circledR}$, Fugi Rebio, Tokyo, Japan). ACE acts on $p$-hydroxylbenzoyl-glycyl-L-histidyl-L-leucine, and separates $p$-hydroxylbenzoic acid and glycine. Quinoneimine dye was produced by oxidation and condensation of the $p$ hydroxylbenzoic acid and 4-aminoantipyrine, using sodium metaperiodate. The concentration of quinoneimine dye was quantitatively measured at its absorbance maximum at 505 $\mathrm{nm}$ to evaluate ACE activity.

All data are expressed as the mean \pm SEM. Analysis by ANOVA was used, followed by Tukey's test. A value of $p<0.05$ was considered statistically significant.

After administering enalapril once or twice a day at 0.25 , 0.5 , and $1.0 \mathrm{mg} / \mathrm{kg}$, plasma ACE activity fell dose-dependently (Figs. 1, 2). The inhibitory effect of $0.25 \mathrm{mg} / \mathrm{kg}$ (decreased by $23 \pm 5 \%: n=7$ ) administered once a day after $24 \mathrm{hr}$ revealed almost half $(p<0.005)$ of that of twice a day $(41 \pm 5 \%: n=8)$, while the effects of $0.5(39 \pm 5 \%: n=6,36 \pm$ $7 \%: \mathrm{n}=8$, respectively) and $1.0 \mathrm{mg} / \mathrm{kg}(48 \pm 7: \mathrm{n}=6,52 \pm 4 \%$ : $\mathrm{n}=8$, respectively) administered once or twice a day were not different.

Heart rate was not affected by enalapril dose or administration time (Tables 1,2). The systolic blood pressure was significantly decreased after $3 \mathrm{hr}$ with $0.25,0.5$ and $1.0 \mathrm{mg} /$ $\mathrm{kg}$ s.i.d. When given twice a day, systolic blood pressure was significantly decreased after 3 and $15 \mathrm{hr}$ at all doses.

Activation of the renin angiotensin aldosterone system and sympathetic tone as compensatory mechanisms is observed in congestive heart failure [9, 15]. Congestive heart failure resulting from chronic valvular disease, dilated cardiomyopathy, and hypertrophic cardiomyopathy in dogs is treated pharmacologically with vasodilating agents, such as hydralazine [17]. However, hydralazine increases plasma aangiotensin II and aldosterone, which stimulate cardiac 


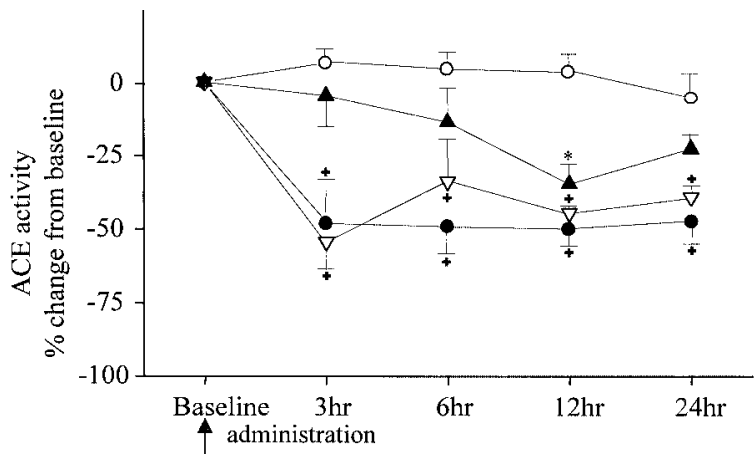

Fig. 1. Plasma angiotensin converting enzyme (ACE) activity with enalapril (s.i.d.) in cats. Enalapril $0.25 \mathrm{mg} / \mathrm{kg}(\boldsymbol{\Delta})$ significantly $(*: p<0.03)$ inhibited ACE activity at $12 \mathrm{hr}$ after administration, comparing with a placebo $(\bigcirc)$. Enalapril 0.5 $\mathrm{mg} / \mathrm{kg}(\nabla)$ or $1.0 \mathrm{mg} / \mathrm{kg}(\bigcirc)$ significantly $(+: p<0.01)$ inhibited ACE activity for $24 \mathrm{hr}$ compared with a placebo.

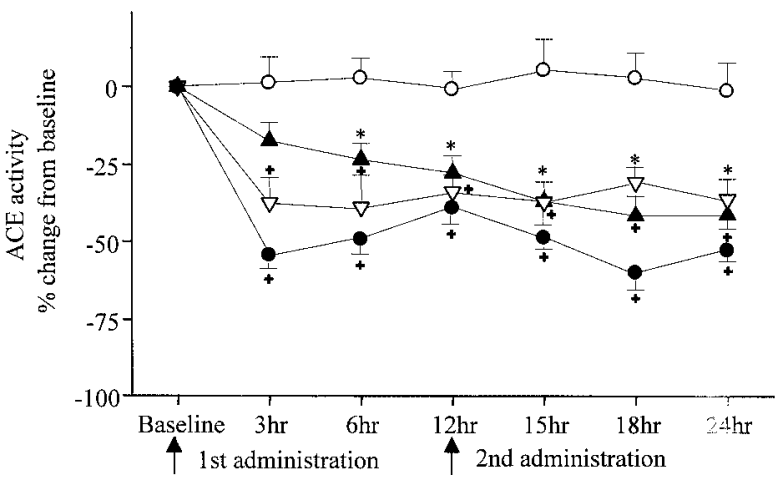

Fig. 2. Plasma angiotensin converting enzyme (ACE) activity with enalapril (b.i.d.) in cats. Enalapril $0.25 \mathrm{mg} / \mathrm{kg}(\boldsymbol{\Delta})$ significantly $(*: p<0.05)$ inhibited ACE activity at $6-24 \mathrm{hr}$ after administration, comparing with a placebo $(\bigcirc)$. Enalapril $0.5 \mathrm{mg} / \mathrm{kg}$ $(\nabla)$ or $1.0 \mathrm{mg} / \mathrm{kg}(\bigcirc)$ significantly $(+: p<0.01)$ inhibited ACE activity for $24 \mathrm{hr}$ compared with a placebo.

Table 1. The hemodynamic effects of enalapril once a day administration

\begin{tabular}{|c|c|c|c|c|c|c|}
\hline & \multicolumn{2}{|c|}{$\downarrow_{\text {administration }}$} & \multicolumn{3}{|c|}{$\%$ of changes from baseline } \\
\hline & & Baseline & $3 \mathrm{hr}$ & $6 \mathrm{hr}$ & $12 \mathrm{hr}$ & $24 \mathrm{hr}$ \\
\hline Heart rate & Placebo & $195 \pm 26$ & $2 \pm 7$ & $-2 \pm 4$ & $-3 \pm 5$ & $-2 \pm 4$ \\
\hline \multirow{3}{*}{ (beats $/ \mathrm{min}$ ) } & $0.25 \mathrm{mg} / \mathrm{kg}$ & $184 \pm 31$ & $2 \pm 3$ & $5 \pm 3$ & $3 \pm 3$ & $2 \pm 2$ \\
\hline & $0.5 \mathrm{mg} / \mathrm{kg}$ & $186 \pm 29$ & $1 \pm 3$ & $5 \pm 5$ & $-1 \pm 2$ & $1 \pm 3$ \\
\hline & $1.0 \mathrm{mg} / \mathrm{kg}$ & $189 \pm 21$ & $2 \pm 4$ & $2 \pm 3$ & $5 \pm 4$ & $5 \pm 4$ \\
\hline SBP & Placebo & $122 \pm 21$ & $2 \pm 3$ & $-5 \pm 5$ & $-4 \pm 7$ & $-3 \pm 5$ \\
\hline \multirow{3}{*}{$(\mathrm{mmHg})$} & $0.25 \mathrm{mg} / \mathrm{kg}$ & $125 \pm 7$ & $-8 \pm 2 *$ & $-4 \pm 4$ & $-4 \pm 3$ & $7 \pm 3$ \\
\hline & $0.5 \mathrm{mg} / \mathrm{kg}$ & $123 \pm 11$ & $-15 \pm 3 *$ & $-8 \pm 4$ & $-2 \pm 2$ & $1 \pm 5$ \\
\hline & $1.0 \mathrm{mg} / \mathrm{kg}$ & $121 \pm 8$ & $-14 \pm 2 * *$ & $-13 \pm 2 * *$ & $-7 \pm 3$ & $-3 \pm 2$ \\
\hline MBP & Placebo & $86 \pm 14$ & $1 \pm 4$ & $-7 \pm 4$ & $-9 \pm 4$ & $-2 \pm 5$ \\
\hline \multirow[t]{3}{*}{$(\mathrm{mmHg})$} & $0.25 \mathrm{mg} / \mathrm{kg}$ & $89 \pm 12$ & $-15 \pm 2 *$ & $-8 \pm 4$ & $-7 \pm 5$ & $-2 \pm 7$ \\
\hline & $0.5 \mathrm{mg} / \mathrm{kg}$ & $83 \pm 10$ & $-14 \pm 5^{*}$ & $-3 \pm 4$ & $3 \pm 6$ & $3 \pm 6$ \\
\hline & $1.0 \mathrm{mg} / \mathrm{kg}$ & $88 \pm 13$ & $-23 \pm 4 * *$ & $-20 \pm 5^{* *}$ & $-20 \pm 5$ & $-5 \pm 6$ \\
\hline DBP & Placebo & $69 \pm 12$ & $0 \pm 5$ & $-11 \pm 4$ & $-12 \pm 4$ & $-5 \pm 5$ \\
\hline \multirow[t]{3}{*}{$(\mathrm{mmHg})$} & $0.25 \mathrm{mg} / \mathrm{kg}$ & $73 \pm 10$ & $-18 \pm 1 *$ & $-14 \pm 3^{*}$ & $-13 \pm 4^{*}$ & $-8 \pm 6$ \\
\hline & $0.5 \mathrm{mg} / \mathrm{kg}$ & $73 \pm 16$ & $-18 \pm 7 *$ & $-12 \pm 6$ & $-1 \pm 9$ & $-7 \pm 7$ \\
\hline & $1.0 \mathrm{mg} / \mathrm{kg}$ & $71 \pm 13$ & $-24 \pm 5^{*}$ & $-21 \pm 4^{*}$ & $-19 \pm 9 *$ & $-6 \pm 7$ \\
\hline
\end{tabular}

SBP: systolic blood pressure, MBP: mean blood pressure, DBP: diastolic blood pressure.

* $P<0.05, * * P<0.001$ compared with baseline.

remodeling, whereas ACE inhibitors have less of an effect [6].

In dogs with mitral regurgitation, enalapril $0.5 \mathrm{mg} / \mathrm{kg}$ s.i.d. or b.i.d. improves exercise tolerance and decreases mortality [8]. In the report by the Cooperative Veterinary Enalapril (COVE) Study Group [3], dogs were given enalapril $0.5 \mathrm{mg} / \mathrm{kg}$ s.i.d. or b.i.d., which was effective in ameliorating the clinical signs of heart failure caused by naturally acquired mitral regurgitation and dilated cardiomyopathy. In the report by the Invasive Multi-center Prospective Veterinary Evaluation (IMPROVE) study group [10], dogs were given placebo or enalapril $0.5 \mathrm{mg} / \mathrm{kg}$ b.i.d. for 21 days. By the end of the study, $59 \%$ of the enalapril-treated dogs had improved, according to the assigned class of heart failure.
In dogs with mitral regurgitation, pulmonary congestion impairs pulmonary vasomotion in response to angiotensin II and bradykinin, and this is normalized by ACE inhibitors [18]. These results support the use of ACE inhibitors in the clinical management of chronic congestive heart failure, and enalapril is given to dogs in doses of $0.5 \mathrm{mg} / \mathrm{kg}$ s.i.d. or b.i.d..

Miller et al. [13] reported that enalapril $(0.5 \mathrm{mg} / \mathrm{kg}$, s.i.d.) decreased arterial blood pressure in cats with autosomal dominant polycystic kidney disease using a radiotelemetric system. The depressor effects of enalapril persisted for 24 $\mathrm{hr}$. Our data showed that the depressor effect of enalapril lasted for $3 \mathrm{hr}$. This difference in the depressor response to enalapril may result from the method of blood pressure mea- 
Table 2. The hemodynamic effects of enalapril twice a day administration

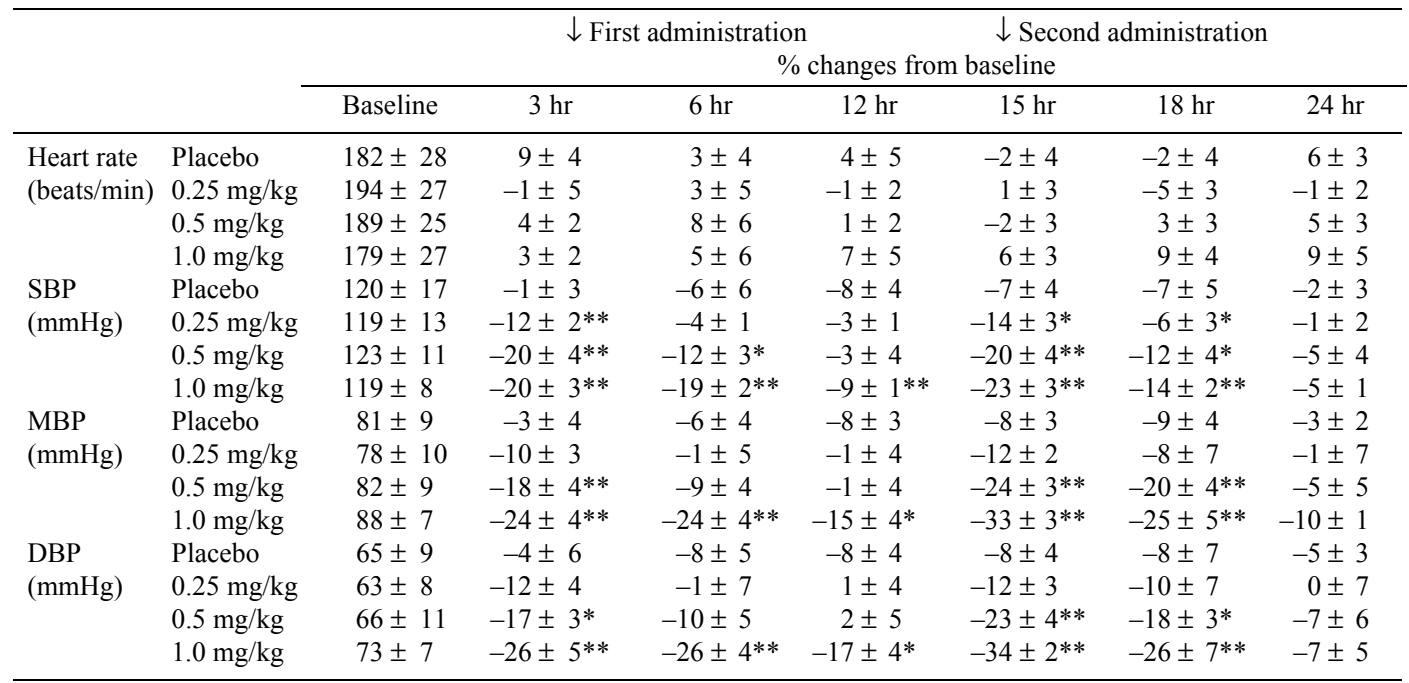

SBP: systolic blood pressure, MBP: mean blood pressure, DBP: diastolic blood pressure. ${ }^{*} P<0.01,{ }^{* *} P<0.001$ compared with baseline

surement. The radiotelemetric system has the advantage of measuring blood pressure in conscious cats, compared with oscillometric methods [2]. Therefore, although we were able to detect the maximum depressor effect of enalapril, our evaluation of the depressor effect of enalapril was limited. In addition, plasma ACE activity and blood pressure fell in dose-dependent manners, and a biphasic response to twice daily administration was seen. Twice daily administration of $0.25 \mathrm{mg} / \mathrm{kg}$ enalapril inhibited plasma ACE activity by $40 \%$ after $24 \mathrm{hr}$, which was essentially the same as the effects of 0.5 and $1.0 \mathrm{mg} / \mathrm{kg}$ s.i.d., and 0.5 and $1.0 \mathrm{mg} / \mathrm{kg}$ b.i.d., while $0.25 \mathrm{mg} / \mathrm{kg}$ administered once a day had a significantly weaker effect. Thus, enalapril with a daily dose exceeding $0.5 \mathrm{mg} / \mathrm{kg}$ may provide similar efficacy of plasma ACE inhibition in cats.

ACKNOWLEDGMENT. This study was supported in part by a Grant-in-Aid for General Scientific Research (C12833009) from the Japanese Ministry of Education, Science and Culture.

\section{REFERENCES}

1. Blackford, L.W., Golden, A.L., Bright, J.M., Bright, R.M. and Gompf, R.E. 1990. Vet. Surg. 19: 237-242.

2. Brown, S.A., Langford, K. and Tarver, S. 1997. Am. J. Vet. Res. 58: 647-652.

3. The COVE Study Group. 1995. J. Vet. Intern. Med. 9: 243252.

4. Eriksson, S.V., Eneroth, P., Kjekshus, J., Offstad, J. and Swedberg, K. 1994. Clin. Cardiol. 17: 603-606.
5. Gavaghan, B.J., Kittleson, M.D. and McAloose, D. 1999. Aust. Vet. J. 77: 574-579.

6. Haggstrom, J., Hansson, K., Karlberg, B.E., Kvart, C., Madej, A. and Olsson, K. 1996. Am. J. Vet. Res. 57: 1645-1652.

7. Häggstrom, J., Hansson, K., Kvart, C., Karlberg, B.E., Vuolteenaho, O. and Olsson, K. 1997. Am. J. Vet. Res. 58: 77-82.

8. Hamlin, R.L., Benitz, A.M., Ericsson, G.F., Cifelli, S. and Daurio, C.P. 1996. J. Vet. Intern. Med. 10: 85-87.

9. Holmer, S.R., Riegger, A.J., Notheis, W.F., Kromer, E.P. and Kochsiek, K. 1987. Basic. Res. Cardiol. 82: 101-108.

10. The IMPROVE Study Group. 1995. J. Vet. Intern. Med. 9: 234-242.

11. Kittlesen, M.D. 1998. Small Animal Cardiovascular Medicine. (Kittleson, M.D. and Kienle, R.D. eds.), Mosby, St. Louis.

12. Littman, M.P. 1994. J. Vet. Intern. Med. 8: 79-86.

13. Miller, R.H., Lehmkuhl, L.B., Smeak, D.D., DiBartola, S.P. and Radin, J. 1999. Am. J. Vet. Res. 60: 1516-1525.

14. Nagata, T., Takemura, N., Washizu, M., Motoyoshi, S., Wakao, Y., Takahashi, M., Matsumoto, H., Yamane, Y. and Roncalli, R.A. 1996. Adv. Anim. Cardiol. 29: 14-26 (in Japanease).

15. Riegger, G.A., Liebau, G., Holzschuh, M., Witkowski, D., Steilner, H. and Kochsiek, K. 1984. Am. J. Cardiol. 53: 614618.

16. Rush, J.E., Freeman, L.M., Brown, D.J. and Smith, F.W. Jr. 1998. J. Am. Anim. Hosp. Assoc. 34: 38-41.

17. Sisson, D. and Kittleson, M.D. 1999. Textbook of Canine and feline cardiology, 2nd ed. (Fox, P.R., Sisso,n D. and Moise, N.S. eds), W.B. Saunders Company, Pennsylvania.

18. Straeter-Knowlen, I.M., Dell'italia, L.J., Dai, J., Hankes, G.H., Dillon, A.R., Cartee, R.E., Pohost, G.M. and Ku, D.D. 1999. Am. J. Physiol. 277: H1924-H1930.

19. Swedberg, K., Kjekshus, J. and Snapinn, S. 1999. Eur. Heart J. 20: $136-139$. 